The University of Akron

\title{
IdeaExchange@UAkron
}

Proceedings from the Document Academy

University of Akron Press Managed

June 2016

\section{Transformations: From Social Media Campaign to Scholarly Paper}

Hilary Yerbury

University of Technology Sydney, hilary.yerbury@uts.edu.au

Ahmed Shahid

University of Sydney, gaafarushahid@gmail.com

Please take a moment to share how this work helps you through this survey. Your feedback will be important as we plan further development of our repository.

Follow this and additional works at: https://ideaexchange.uakron.edu/docam

Part of the Library and Information Science Commons

\section{Recommended Citation}

Yerbury, Hilary and Shahid, Ahmed (2016) "Transformations: From Social Media Campaign to Scholarly Paper," Proceedings from the Document Academy: Vol. 3 : Iss. 1 , Article 12.

DOI: https://doi.org/10.35492/docam/3/1/12

Available at: https://ideaexchange.uakron.edu/docam/vol3/iss1/12

This Article is brought to you for free and open access by University of Akron Press Managed at IdeaExchange@UAkron, the institutional repository of The University of Akron in Akron, Ohio, USA. It has been accepted for inclusion in Proceedings from the Document Academy by an authorized administrator of

IdeaExchange@UAkron.For more information, please contact mjon@uakron.edu, uapress@uakron.edu. 


\section{INTRODUCTION}

At the 2015 meeting of the Document Academy, we presented a study of a social media human rights campaign about the disappearance of a journalist in Maldives, analysing the relationships between the posts of the campaign and the documents from NGOs, governments and the United Nations responding to the social media discourse. In the discussion after the presentation, Professor Geoffrey Bowker asked if we had considered the relationships between the posts of the campaign and our own scholarly paper. This was a challenge that we accepted and this paper presents our interpretation of the relationships between the posts, comments and tweets of the social media campaign and the paper now published in the Proceedings of the Meeting of the Document Academy 2015 (Yerbury and Shahid, 2015).

The original study set out to explore how an understanding of the genre of a human rights document could shed light on the posts, comments and tweets of a social media campaign and the texts developed from the message of the campaign. The campaign was instigated in August 2014 by the friends and family of a young Maldivian journalist who had disappeared, presumed abducted, to prompt the police to conduct a thorough investigation and provide some answers about his disappearance. The campaign, under the tagline Find Moyameehaa, used a website, facebook and twitter ${ }^{1}$. In its first hundred days, the campaign did not result in any answers from the government nor did it prompt a thorough investigation by the police. However, it did lead to a range of outcomes, including a formal statement from Amnesty International, an agenda item from the UN and speeches or questions in the Parliaments of Australia, Canada and the UK among others.

We designed a study using Genette's notion of transtextuality (1997) to explore the standing of the posts, comments and tweets from this campaign and their relationship to other texts to determine whether they and the other texts, outcomes produced by other organisations, met the requirements for a human rights document. For Genette, transtextuality is "all that sets the text in a relationship, whether obvious or concealed, with other texts" (1997, p. 1). His concern was to show that all published texts were linked to other texts, networked in some way. From this basic notion, he established five types of textual relationships. The first is intertextuality, where content from one text is inserted in another, usually through the conventional process of quoting; the second is paratextuality, a process involving content which surrounds and situates the text, making it more accessible, for example through a preface or foreword; the third is metatextuality, which permits commentary on the original; the next is architextuality, which links a text to others of the same genre. The final type is

${ }^{1}$ www.findmoyameehaa.com; https://www.facebook.com/findmoyameehaa; and \#FindMoyameehaa. 
hypertextuality, which is concerned with the relationship between text A and text B; where B cannot exist without A (Genette, 1997, pp. 1-7). The original text can thus be referred to as a hypotext.

Using this analytical frame and the processes and characteristics of a human rights document (Guzman and Verstappen, 2003), we concluded that the Facebook posts, tweets and website on which the social media campaign was based did not constitute a human rights document; they do not encapsulate the documentary practices of witnessing and of human rights notifications. Rather, they represent a series of lacks - lack of evidence, lack of documentary practices, lack of bureaucratic processes, lack of political will and even lack of compassion towards a grieving mother - which, in human rights terms, permit the creation of other documents.

Witnessing is something of a vexed concept in human rights practice, with its quasi-legal sense that somebody saw an abuse of human rights taking place and reported it to an organisation which was in a position to document it, verify it and to take some action (McClintock, 2012). A broader conception of witnessing is being adopted through the use of interactive technologies, in projects such as The Whistle ${ }^{2}$ which is a digital human rights reporting platform that connects civilian witnesses and human rights NGOs by supporting the verification process. McPherson, the leader of this Economic and Social Research Council project, notes (2015) that civilian witnesses may have problems in getting their social media information verified because they may not have access to an appropriate network.

From a documentation perspective, it is the voice of a writer that is significant, rather than the report of witnessing an action, with the document itself 'standing in' for the writer (Levy, 2001, p. 31). For Levy (2001, p. 26) this sums up the purpose of a document: "Documents are exactly those things we create to speak for us, on our behalf and in our absence". In the case of the FindMoyameehaa campaign, the instigators are not witnesses, in the human rights sense. However, they seem to recognise the power of the document: although the instigators describe themselves as family and friends, and although they have no documented evidence of the moment of disappearance, one of the participants noted, 'We are not a bunch of nobodies without voice or an audience' (Facebook post, 23 August 2014). Being able to use social media effectively to disseminate the message of the journalist's alleged abduction may have had some impact on the influence of the campaign. Genette's notion of transtextuality made evident the relationships between the social media campaign, the notion of a human rights document and the texts created after the involvement of a range of different organisations; these texts are, clearly, human rights documents. The analysis

\footnotetext{
${ }^{2}$ http://www.smhr.sociology.cam.ac.uk/
} 
demonstrated the relationships and the transformations which co-existed between the text of the posts, comments and tweets of the social media campaign and the texts from the various organisations, with a particular focus on the transformations that led to them being seen as human rights documents.

\section{LINKING THE FINDMOYAMEEHAA CAMPAIGN AND THE DOCAM PAPER}

The purpose of this linking of the social media campaign and the published scholarly paper is not to answer the question of whether either or both can be perceived as a document, but to explore the ways they are related and the processes through which the paper transforms the posts, comments and tweets of the campaign to create a document. Following Buckland (1997), Frohmann (2009) and Lund (2009), we acknowledge that there is little value in discussing definitions and criteria by which either the posts, comments and tweets or the scholarly paper can be considered a document. We continue the approach from the original study, which recognised the value in considering a document as text which could facilitate an understanding of the complexities of communications in social media and the relationships among and between people and among and between messages. Thus, Genette's notion of transtextuality is important to this investigation. His concern was to show that all published texts were linked to other texts, networked in some way. Equally important is Frohmann's (2009) argument that our understanding of a document and the justification of that understanding are to be found in the "the stories we tell", the ways in which we talk about documentation and the document. These stories are not always the same, so one may find different justifications for the same action but also disagreements on what are appropriate actions. At a more practical level, there are papers which draw the attention of the researcher to issues and problems involved in using social media sources as case study material or evidence in a study (eg boyd, 2009, King, 2011, Weller, 2015), which bring into focus the perspectives of the researcher and of the users of social media.

The complexity of the links between the FindMoyameehaa campaign and the DOCAM paper will be set out in three themes which themselves are fundamental to an understanding of documentation. These themes are labelled Demonstrating Relationships, Transformations and the Stories We Tell. The notion of demonstrating relationships is inherent in one of the classic texts, Suzanne Briet's What is Documentation? Here, she sets out the idea of an 'initial' document giving rise to 'secondary or derived' documents, a 'documentary fertility' which she encourages us to admire (Briet, 2006, pp. 10-11). The notion of transformations can also be seen in this early work; however, perhaps more relevant to this current discussion is the notions of fixity and fluidity explored by Levy (1994). He argues that documents must be conceptualised as being fixed and 
unchanging on the one hand but fluid and capable of change on the other hand. His discussion of the fixed and the fluid in hypertextual relationships, while concerned with a particular technology, raises questions about the documentary systems that can emerge as a result of Briet's documentary fertility. Levy's idea (2001, pp. 26-31) that not only do we use documents to tell stories but that documents 'stand in' for us, they speak for $u s$, in our absence is relevant to the discussion of the theme of the stories we tell through our practices.

Demonstrating these relationships will start from the existence of the DOCAM paper, examining how what Genette refers to as its architextuality - its genre - is fundamentally based on the notion of relationships with previous scholarly work and with evidence from a new study. It considers the role of intertextuality in creating a relationship based on quotation and allusion and explores hypertextuality as a way of indicating that, without the hypotext of the posts, comments and tweets, the paper could not exist. The section on Transformations starts from metatextuality, commentary on a text. It is also concerned with the ways in which researchers transform social media into data and data into a report of research and the ways in which the technologies of the social media affect the actions and expressions of those who use them. Finally the theme of 'the stories we tell' picks up on the genre of the scholarly article, showing that there is more than one way to enact the genre, discusses Genette's notion of paratextuality and concludes by showing how stories of hypotextual relationships exist even when the original is not mentioned.

\section{DEMONSTRATING RELATIONSHIPS}

Briet (2006) would argue that the journal article is a document derived from the initial text of the social media campaign and thus a clear relationship exists. Genette's analysis takes a more nuanced approach. Following Genette, the conference paper at the centre of this analysis is part of a web of relationships with other texts. Architextuality, the genre of the text, is an essential starting point for noting relationships among and between texts (Genette, 1997, p. 4). A scholarly research article, such as this conference paper, has a clearly defined set of characteristics, usually including a research question, a review of the literature on the topic, a description of how the research question will be answered, an exposition of the evidence gathered to answer the question and a discussion of the relationship of this evidence to the findings of previous studies. The genre itself assumes a networking of ideas and evidence demonstrated through a process of argument. Thus, the social media campaign, its posts, comments and tweets, and the associated documents are inextricably linked to the DOCAM paper, since they provide the evidence on which the research question is based.

Going further, the form of publishing the scholarly article, in the online proceedings of the meeting of the Document Academy, makes it an example of a 
sub-genre of academic publishing, open access publishing. The Proceeding of the Meetings of the Document Academy are what is known as diamond open access (cf Fuchs and Sandoval, 2013, p. 438) the most accessible category, being available without payment by either the author or the reader and without a requirement for registration or membership, an ideological position facilitating the widespread dissemination of scholarly work to anyone with access to a networked computer. The technologies available for open access online scholarly publishing vary in their sophistication and their abilities to position an article in the broader scholarship in the field. The technology used here, Digital Commons developed by Berkeley Electronic Press for use with digital repositories in universities, and research centres in the US, is at the less sophisticated end of the spectrum. It provides hot links to the FindMoyameehaa website and Facebook page but no links to the scholarly references, yet still enables material to be found through Google, Google Scholar and other databases as well as through the Digital Commons Network. Thus, the published paper is well networked, through the tools of digital scholarship. In particular, the Digital Commons technology allows authors to know how many times a document has been downloaded and the city and country where the readers are. Although the specific identity of the reader is not revealed, there is a sense in which through technological mediation these readers are not invisible in the way boyd (2009) indicates readers of social media may be. The link to Scholar Google can identify those papers which have cited the published conference paper and create a hyperlink to them; in this instance, the scholar involved is identified as is the way in which the two documents are linked. This linking through the power of the technology opens the possibility of relationships with the FindMoyameehaa campaign being created way beyond the original study.

Returning to the first-level relationships, relationships between texts are created through intertextuality, the use of quotations and allusions. This process is fundamental to the development of this scholarly argument and works at two levels. Firstly, quotations are used to substantiate the argument of the paper, that the social media campaign is essentially a set of commentaries on the original statement of Rilwan's disappearance. Quotes also show how expressions of emotion fill the gap left by lack of information and they give an impression of popular culture through the range of media used to express these emotions. They are, finally, used to give a glimpse of contemporary debates in Maldivian society, showing something of the relationships between Maldivian citizens and the government. These quotes are fundamental to the scholarly argument, demonstrating a relationship between the paper and the posts, comments and tweets which is so fundamental that without them, the paper cannot exist. Secondly, through the use of references to other studies, this paper shows that the interpretations being made in this study have been made previously in other 
scholarly contexts and in doing this, it locates the campaign in a new and different network, creating relationships that neither the participants in the social media campaign nor the authors of the scholarly articles could have imagined.

\section{TRANSFORMATIONS}

The act of carrying out the study led to a series of transformations of the posts, comments and tweets, raising questions of fixity and fluidity as Levy (1994) discussed. These are transformations of meaning, transformations into artefacts of research and transformations of the relationships which the writers have with the text. The process of transformation is apparent in Genette's category of metatextuality, which involves critical commentary on an original text. When the original text comes from social media, such as Facebook or Twitter, understanding transformation becomes more complex.

In a study involving social media, the metatextual relationship can be seen as the process of turning everyday experiences, recorded in Facebook posts and comments and tweets, into data so that they can then be commented upon. In the first instance, this can be taken as a process of abstraction, a way of seeing the posts, comments and tweets of very many people not as a series of individual entities but as a whole, a narrative of collective experiences and expressions of emotion. From this process of analysis and synthesis arise the symbols and memes which exemplify a collectivity of sentiment and which can act as a shorthand to evoke the feelings of the participants in the campaign. This transformation of individual experiences and expressions into data facilitates the suggestion that a collectivity exists, not yet a social movement with the features identified by Castells (2012) but nonetheless, a group expressing despair and hope, formulating actions to address their concerns and using social media to do so. These symbols are identified and communicated through the published paper as including the passage of time since Rilwan disappeared, exemplified in the endlessly repeated statement of the days, hours and minutes since Rilwan's disappearance, and the sorrow of Rilwan's parents, expressed in photos taken of them in public protests, with one of the photos of his mother becoming a poster and rallying image for a part of the campaign. They go some way to creating common ground between the reader of the scholarly paper and the men and women who have contributed to the social media campaign, bridging the gap to make the everyday experiences expressed through social media understandable to those reading in other parts of the world. Another symbol, the use of the question mark in the Thaana script, ?, both as a twibbon in Twitter and as the basis for creating a portrait of Rilwan, evokes the unanswered questions on which the campaign is based. The use of the hashtag \#FindMoyameehaa makes clear the purpose of the campaign to monolingual English speakers, but speakers of Dhivehi are urging others to 
'\#Find A Madman' and those Maldivians who have cherished freedom of speech are noting the loss of a champion, whose bloghandle was Moyameehaa.

This process of transformation can be considered from the perspective of the practice of the researcher, transforming data into evidence to support an argument. Here, when the data derive from social media sources, the concerns may be with the completeness of the data and the command of the tools to analyse it. King (2011), commenting on the value of real time data for research in the social sciences, notes that access to social media posts provides another avenue for understanding the opinions of citizens on an issue, adding to the commonly used option of the random survey. This process of transforming social media posts into research data is not unproblematic. Weller states that whereas some researchers are so focused on the digital patterns emerging through social media usage that they may almost forget that there are actual users, other are so focussed on the user perspectives that they overlook the impact of the technologies that allow the perspectives to emerge $(2015$, p. 281). Our focus was on the users and their engagement in this social media campaign, but we did not completely overlook the technological aspect. We sought to sidestep the problems caused by the 'ever-changing nature' of social media (Weller, 2015, p. 287). Having decided to focus on the campaign over the one hundred days from the disappearance of Rilwan, we also made the decision to accept the posts, comments and tweets as they were on that day as presented by the technologies of the website, Facebook and Twitter. We printed out the Facebook posts and we printed Twitter's Top Tweets for the \#FindMoyameehaa for the same period. In this way, we stopped the movement inherent in social media and, in Levy's terms, created fixity (1994). This meant that we did not have a record of the real-time creation of the social media campaign; we acknowledged that there may have been posts that were deleted. Perhaps more significantly, we recognised that in using the Top Tweets, we were accepting a transformation of the everyday already implemented by Twitter, with no clear understanding of exactly how top tweets were derived (Twitter n.d.). But, we had created immutable data, albeit data with potential flaws. Our immutable data presented us with another challenge - the posts, comments and tweets were not all written in English, although the majority were: some were written in English and Dhivehi and some in Romanised Dhivehi. Images and linked documents from Maldives were likely to be written in Dhivehi, in Thaana script. The technological tools for managing bi-lingual data of this kind appears not to be available, another reason why we opted for the printouts. We chose to use a 'pencil and paper' method for recording our analysis of the content of the posts, comments and tweets, acknowledging the human process of interpretation of the data, the bi-lingual nature of the posts and the lack of command of Dhivehi of one of the researchers. Our methodology, then, could be challenged for lacking rigour, not following the convention of the use of some 
technology for managing the data. In a review of another paper exploring notions of emotion and political accountability in this social media campaign, our methodology was challenged - not for incomplete data, but for not using computer software to analyse the posts, comments and tweets.

The process of transformation can also be considered from the perspective of the individual whose posts, comments or tweets may be part of the body of data being analysed. Here, the concern may be with unknown people reading posts, statements being taken out of context and with issues of the public and the private. boyd (2009) notes that there are three aspects of the digitised communications of social media that affect relationships, an invisible audience, a lack of boundaries in time, space or social interactions and a blurring of the line between notions of public and private. As we transformed the experiences of everyday life into research data, we were an invisible audience for those posting on Facebook and Twitter. They would have been completely unaware of us, our reading of their posts and tweets and our offline analysis of these expressions of their thoughts and actions. In our analysis, we did not record the identity of those posting in the campaign nor where they were located but we were interested in the way in which the social media campaign was able to move beyond the Maldivian context from which the campaign emerged. To that extent, we did not establish boundaries in space; we were criticised by another reviewer of the submission referred to above for not establishing in the title of the submission that the social media campaign was bounded by space. Although we carried out the analysis after the 100 days of the campaign, we recognised that marking the passage of time was a significant factor for people engaged in this campaign, marking the hours and days that Rilwan had been missing, and included this as a meme in the published paper.

Equally significant for this exploration of the relationships between the posts, comments and tweets of a social media campaign and the published report of the study is the question of the public and the private. Tweets, intended as they are for a broad audience, are generally not considered private communications, but with Facebook posts, being potentially private communications but publicly accessible, the argument is not so clear. We took the view that the tweets using the hashtag \#FindMoyameehaa were public and intended to be so. The website and Facebook page were set up to seek information about Rilwan's disappearance and to communicate information about plans for action; this was made clear in the 'about' section, thus position it as a public space. To this extent, it is possible to consider these platforms as being expressions of a kind of public sphere (Habermas, 1992), offering a possibility for anyone to participate in the campaign and its debates. However, the Facebook page became a focus for expressions of grief and frustration by friends as well as by people who identified themselves as strangers; and while these form part of the public record of the campaign, some were clearly personal statements, not part of a public sphere. The campaign itself 
could be seen as a political action, drawing attention to the apparent lack of action of the police in investigating the disappearance of the journalist; posts, comments and tweets report on the attempts of the family to prompt the police to action. Tweets and posts from some others are also political actions, critical of the police and of the government. In a country slipping away from democratic practices (Mulberry, 2014), we confronted the situation expressed so clearly by boyd and Crawford (2012, p.671): “just because it is accessible doesn't make it ethical".

The transformation of the social media campaign posts into data for a scholarly paper thus raised a question about the naming of individuals as authors of posts and tweets; some individuals were clearly significant contributors not only to this campaign but to broader debates on democracy and freedoms. It was easy to use Google to identify many contributors directly; some used a pseudonym but it was still easy to piece together information to identify them; a few used a pseudonym that could not be related back to a named individual. A convention of research practices dictates that a source of data be identified. However, it was the text that was important to our argument about transformations - what was written or presented, rather than who wrote it.

We created a section in the published paper entitled 'Becoming something else'. Here we focused on something beyond Levy's notion of fluidity; which seems more concerned with the artefact and the way it is perceived (1994, p. 30). Instead, we focused on how the use of Genette's notion of transtextuality was able to demonstrate that social media enabled text which originally clearly was in one category of transtextuality to transform into another. A key example of that was the creation of memes. It was not important to know who echoed the passage of time, only that so many people did so that it became a refrain in the campaign. The photograph of Rilwan's mother, taken at one of the gatherings, was an example of a post that transformed from being a text in its own right to becoming a quotation (intertext) and then becoming an expression of collective sadness (metatext).

Creating a hypertext involves a process of transformation as Genette asserts (1997, pp. 5-7) where a second text becomes possible because of the existence of the first, perhaps much as Briet considered primary and secondary documents. In the original study, the concern was to show how the posts, comments and tweets led to the emergence of a range of hypertexts - human rights documents - and this transformation was flagged in the title - the becoming of a human rights document. Similarly, the development of a scholarly paper also involves the transformation of ideas from existing scholarly works and evidence through a rational process which, in the social sciences, bring the possibility of new understandings. Thus, the published paper is clearly a hypertext, with the posts, comments and tweets of the social media campaign as the hypotext, the base without which the published paper would not have come into existence. 
This paper exemplifies Levy's notion of fluidity (1994) in its own development. Our files show that we had worked on several drafts, which we exchanged and commented on. It was the fourth completed version that was regarded as fixed and submitted. The process of review caused that fixity to disappear as the text of the paper entered another phase of fluidity as we worked through other versions on our way to an agreed and therefore fixed text. The editorial process may introduce other aspects of fluidity before the final, authorised, version of the paper is published.

\section{THE STORIES WE TELL}

As a preface to this section, it is important to acknowledge that the story we have told is based on the stories told by others, whose posts, comments and tweets in the social media campaign left powerful traces. Without these stories, there was no basis for our study.

Researchers are essentially storytellers, making public the outcomes of investigation and the assumptions from which they undertook the investigation. In writing a paper for publication, we use a form of storytelling scholars acknowledge as being appropriate for the purpose of creating new understandings. A study may be telling the same story as has been told many times before, but with a different setting or different characters or even a different ending; that is, it may use a conceptual model or a theory which has been tested many times before, but will seek to extend the understanding by implementing it in a different context or with a different type of participant. This form of storytelling is monitored by a process of review, where other scholars indicate whether or not a particular article is suitable to be made public. From this perspective, the data, the posts and tweets from the social media campaign are the material on which the tool of theory works. The paper has been published as a peer reviewed contribution to the proceedings of the Document Academy meeting of 2015. Thus, it follows that the method and the data used, the posts and tweets, were considered appropriate. The anonymous reviewer of another paper using the same social media campaign to explore grassroots' collective action tells a different story. In his or her story, there are 'two main setbacks [in the paper]. One of them is the material used: tweets and Facebook'. The inference is that this leads to a fundamental weakness in the study. The editor of that journal, therefore, concluded that this was a story that should not be told in public.

As storytellers, it can reasonably be assumed that we will have told stories before, based on this or some other study. This story is not told using the disembodied voice of some academic writing, "the voice from nowhere" criticised by Haraway (1988). Our names as authors of this paper form part of Genette's paratext. As authors, we are acknowledged as storytellers; a Google search on our names links us to previous stories we have told, each from our distinct cultural 
and disciplinary context. The backstory we might tell here is of our own transformation in writing this paper, from independent storytellers to a collaborative partnership of storytelling, bridging the gaps between languages and cultural experiences and across disciplines and fields of practice.

Self-citing is another way of telling a story of the link between current work and previous work. In this way, the network of articles by a given author becomes apparent. We have not linked this study to our previous work together, nor to our work done separately. This seems to be an instance where, in Genette's terms, we have created a hypertext, the paper entitled 'The Becoming of a Human Rights Document', without acknowledging its other hypotexts, that is our previous published papers, written together or separately. Analysis of this previous work would show an emphasis on human rights and democratic values, especially as expressed in the work of Keck and Sikkink (1999), Risse and Sikkink (1999) and Giddens (1991). It would have shown that our work can be seen in the utopian tradition of studies of social media (Zemmels 2012), sharing the enthusiasm for the possibilities of social media enhancing opportunities for civic engagement (eg Bakardijeva 2009). It would also have shown our concerns for active citizenship and for issues and practices of human rights.

There is one last piece of storytelling to offer here. The understandings gleaned from linking with these unmentioned hypotexts would perhaps indicate that a final link between the social media campaign and the scholarly paper is that the writing of the paper is itself a form of activism. The conference paper draws attention to an event in a part of the world that few people are familiar with, except perhaps as a holiday destination, and shows how local citizens, human rights bodies and the institutions of that state, that is the police service, parliament and even the president interacted with each other and with the event, the disappearance of a young journalist, during the first hundred days of the social media campaign to prompt action on his alleged abduction. It is also a way of considering human rights practices, showing how major agencies take up reports of human rights abuses and make statements, either as press releases aimed at no one in particular or at particular groups such as the United Nations or even as questions addressed to a government. We have no way of knowing whether readers of our paper have become active in the social media campaign; there has been a small increase in Facebook likes since the original conference presentation but we know from the data supplied by the Document Academy's publishing software that none of the 60+ readers of the paper currently lives in Maldives. Through this focus on human rights practices, the published paper broadens the understanding of what success in a grass roots action through social media might constitute: action that leads to formal statements by national, international or supra-national bodies must be considered successful, even if the accepted 
understanding of success is action by the government where the campaign is taking place.

\section{CONCLUSION}

This paper took up the challenge to explore relationships between a published paper and a social media campaign. It has suggested that these relationships can be conceptualised in three ways: relationships which emerge from the links created between the content of the published paper and the content of the social media campaign posts, comments and tweets and those which emerge through the technology of online publishing; transformations which emerge as the social media campaign is incorporated into the scholarly work; and the stories we tell directly and indirectly through our practices of scholarship.

This descriptive piece brings together several elements in the process of exploring this relationship. Firstly, Genette's concept of transtextuality has been fundamental in showing that texts are linked at several levels and in many ways and these links are more complex and nuanced than the simple division between primary and secondary documents suggested by Briet (2006). Although transtextuality assumes the primacy of text, it acknowledges multiple authors and readers and the impact of context, leading to transformations both acknowledged and unacknowledged. As Genette noted (1997, p. 1), the use of the framework of transtextuality has brought potentially concealed relationships with other texts to our attention. Architextuality, the understanding of genre and links among examples of the same genre, was a strong starting point for elucidating the complexities of the ways in which the genre of scholarly paper works and how a particular example of the genre is linked into other examples and, in this case, into another genre, the social media campaign. Metatextuality, concerned with commentaries on an original text, was found to be very useful in exploring wideranging transformations in documents. In particular, the analysis of these transformations brought to light a range of issues emerging from their interpretation. This was significant in showing the importance of context in understanding documents and their relevance. It was also useful in shedding light on how intangibles such as fixity and fluidity in documents can emerge from work practices.

Secondly, the role of technology has been significant and has worked together with Genette's conceptual framework to bring a more nuanced understanding of the relationships among and between texts. The technology of social media has created complex relationships between the texts of the posts, comments and tweets and the published paper as well as relationships between the authors and the data, the writers of the posts and the posts and the writers of the posts and the authors, following Levy's proposition (2001) that documents can stand in for the writer. The technology of online publishing has set up a different 
set of relationships between the published paper and other published papers, between the published paper and its readers and between the authors and range of indexes and sources of access to the published paper. This notion of bibliometric links is not new, but here, it is suggested that conceptualised in this way, the links show the importance of context and the way in which decisions about the use of publishing technology can facilitate the creation of links beyond those of citing and cited papers.

Finally, a consideration of the ways an author positions the work, giving a focus on the broader context of scholarly and professional practices demonstrates the importance of Frohmann's emphasis on 'the stories we tell' as we justify the documents we create. The paper is not presented as an objective, third person account, presented by disembodied individuals, but rather as a situated 'story'. In this instance, the published paper 'The Becoming of a Human Rights Document' becomes situated in a societal context of campaigning against violations of human rights, showing its authors as scholars engaged in significant societal issues.

\section{REFERENCES}

Bakardjieva, M. 2009, 'Subactivism: Lifeworld and politics in the age of the internet', The Information Society, vol. 25, no. 2, pp. 91-104.

boyd, d. 2009, 'Social media is here to stay... now what?' Microsoft Research Tech Fest, Redmond, Washington, February 26. Available at: http://www.danah.org/papers/talks/MSRTechFest2009.html

boyd. D. and Crawford, K. 2012, 'Critical questions for big data', Information, Communication \& Society, vol. 15, no. 5, pp. 662-679, DOI: http://dx.doi.org/10.1080/1369118X.2012.678878

Briet, S. 2006, What is documentation? English translation of the classic French text. Tr. and ed. R.E Day and L. Martinet. Lanham, Md., Scarecrow Press.

Buckland, M. 1997, 'What is a document?' Journal of the American Society for Information Science, vol. 48, no. 9, pp. 804-809.

Castells, M. 2012, Networks of Outrage and Hope: Social Movements in the Internet Age, Polity Press, Cambridge.

Frohmann, B. 2009, 'Revisiting 'what is a document?' Journal of Documentation, vol. 65 , no. 2 , pp. 291-303.

Fuchs, C. and Sandoval, M. 2013, 'The diamond model of open access publishing: why policy makers, scholars, universities, libraries, labour unions and the publishing world need to take non-commercial, non-profit open access serious', triple $C$, vol. 13, no. 2, pp. 428-443. Available at http://www.triplec.at/index.php/tripleC/article/viewFile/502/497

Genette, G. 1997, Palimpsests: Literature in the second degree, University of Nebraska Press, Lincoln, Nebraska.

Giddens, A. 1991, The Consequences of Modernity, Polity Press, Cambridge. 
Guzman, M. and Verstappen, B. 2003. What is Documentation? Huridocs, Versoix. Available at: http://www.huridocs.org/wpcontent/uploads/2010/08/whatisdocumentation-eng.pdf

Habermas, J. 1992, The Structural Transformation of the Public Sphere; An inquiry into a category of bourgeois society, MIT Press, Cambridge, Mass.

Haraway, D. 1988, 'Situated knowledges: The science question in Feminism and the privilege of partial perspectives', Feminist Studies, vol. 14, no.3, pp. 575-599.

Keck, M. \& Sikkink, K. 1999, 'Transnational advocacy networks in international and regional politics', International Social Science Journal, vol.51, no. 159, pp. 89-101.

King, G. 2011, 'Ensuring the data-rich future of the social sciences', Science, vol. 331, no. 6018, 719-721. DOI: http://dx.doi.org/10.1126/science.1197872 . Available at: http://nrs.harvard.edu/urn-3:HUL.InstRepos:12724029.

Levy, D. 1994, 'Fixed or fluid? Document stability and new media', ECHT Proceedings of the ACM European Conference on Hypermedia Technology, ACM, New York, NY., pp. 24-31.

- 2001, Scrolling Forward, Arcade Publishing, New York, NY.

Lund, N. 2009, 'Document theory', Annual Review of Information Science and Technology, vol. 43, pp. 399-432.

McPherson, E. 2015, 'Digital human rights reporting by civilian witnesses: surmounting the verification barrier', In R. A. Lind, ed. Produsing Theory in a Digital World 2.0: The Intersection of Audiences and Production in Contemporary Theory, Peter Lang Publishing, New York, pp. 193-209.

McClintock, M. 2012, A Basic approach to Human Rights Research. Available at: http://humanrightshistory.umich.edu/research-and-advocacy/basicapproach-to-human-rights-research/

Mulberry, M. 2014, Democratic decline in the Maldives: will the world wake up? 13 October 2014. Available at: https://www.opendemocracy.net/civilresistance/matt-mulberry/democraticdecline-in-maldives-will-world-wake-up

Risse T. \& Sikkink, K. 1999, 'The socialization of international human rights norms into domestic practices', in Risse, T., Ropp, S. and Sikkink, K. (eds.). The Power of Human Rights: International Norms and Domestic Change, Cambridge University Press, Cambridge, pp. 1-38.

Twitter n.d. FAQs about top search results. Available at: https://support.twitter.com/articles/131209?lang=en\#

Weller, K. 2015, 'Accepting the challenges of social media research', Online Information Review, vol. 39, no.3, pp. 281- 289. http://dx.doi.org/10.1108/OIR-03-2015-0069 
Yerbury, H. and Shahid, A. 2015, 'The becoming of a human rights document; an exploration of a human rights campaign', Proceedings from the Annual Meeting of the Document Academy: vol. 2, Article 1. Available at: http://ideaexchange.uakron.edu/docam/vol2/iss 1/1

Zemmels, D. 2012, 'Youth and new media: studying identity and meaning in an evolving media environment', Communication Research Trends, vol. 31, no.4, pp. 4-22. 